\title{
PRIMERAS JORNADAS DE DOCENCIA E INVESTIGACIÓN DE LA ASOCIACIÓN ARGENTINA DE ANATOMÍA CLÍNICA: Un paso hacia la Integración de la Anatomía con las Ciencias Básicas y la Clínica
}

\author{
Elia del C. Martino \\ Cátedra de Anatomía, Facultad de Ciencias Médicas, Universidad Nacional de Cuyo - \\ Argentina
}

"Muchas cosas se juzgan imposibles de hacer, antes de que estén hechas"

Plinio

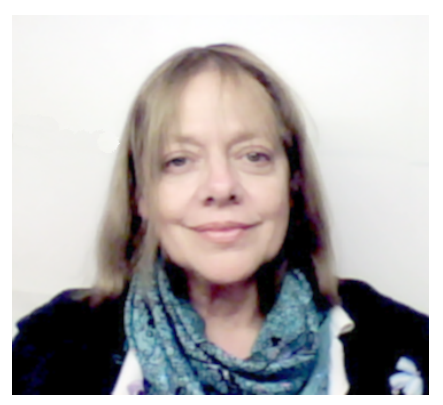

La anatomía ocupa un lugar de privilegio dentro de las ciencias médicas. Sus diferentes aspectos no han perdido actualidad; están vigentes y son de gran importancia en el conocimiento integral del hombre y la base fundamental de la formación médica.

Los anatomistas, como parte de las ciencias morfológicas en sus diferentes modalidades, hemos trabajado en conjunto intentando encontrar el camino que, dentro de la medicina, nos comprometa con todas las disciplinas de las ciencias básicas y de la clínica. Esta coordinación de la enseñanza de la Anatomía se ha hecho necesaria para constituirse en la base sobre la cual se pueden integrar todos los conocimientos que permiten hacer un diagnóstico médico.

Para el logro de este propósito es fundamental establecer los objetivos sobre los cuales debe sustentarse su enseñanza, de acuerdo con las metas que persigue la Unidad Académica en la cual se encuentra inserta.
En la Facultad de Ciencias Médicas de la Universidad Nacional de Cuyo, desde la Anatomía hemos logrado la integración en diferentes niveles:

1) Permitiendo que el alumno integre en su mente los contenidos de la anatomía al mismo tiempo que incorpora conocimientos clínicos en el ciclo básico en ocasión de los casos clínicos estudiados.

2) Formando parte de un curso en donde se han integrado contenidos de diferentes disciplinas: Anatomía Humana Normal, Histología y Diagnóstico por Imágenes.

3) Realizando una integración horizontal y vertical participando directamente en otros cursos del ciclo básico y del clínico

4) Ofreciendo al alumno la posibilidad de construir su aprendizaje en función de la práctica profesional, adquiriendo competencias que tienen como basamento el conocimiento de la Anatomía Normal. Esto se realiza dentro de la oferta de Cursos Optativos en la Práctica Final Obligatoria en el Ciclo Clínico.

5) Participando en la Prueba Global del Ciclo Básico en la que se evalúan conocimientos teóricos y competencias clínicas del estudiante en situaciones clínicas simuladas, a través de la prueba conocida por su sigla en inglés "OSCE"(Objective Structured Clinical Examination). 
Persiguiendo estos objetivos de mayor integración, desde la Asociación Argentina de Anatomía Clínica, queremos contribuir a la formación integral, general y profesional realizando actividades vinculadas con la asistencia médica, la docencia y la investigación. Esto no sería posible sin la generación de un espacio para la comunicación y el fortalecimiento de la integración de toda la comunidad académico-científica.

Por este motivo estamos organizando las "Primeras Jornadas de Docencia e Investigación de la Asociación Argentina de Anatomía Clínica", que tendrán lugar en Mendoza en setiembre de 2010.
El objetivo específico de esta Jornadas es participar en los últimos avances en el diagnóstico por imágenes, en la investigación de las ciencias básicas y su integración con las clínicas. Asimismo, en la modernización de la enseñanza de grado, en la que es una premisa la integración horizontal y vertical con el resto de las disciplinas que conforman el plan de estudio. De esta manera será posible lograr un perfil profesional que se adapte a las demandas y a las características de la sociedad del siglo XXI.

Los invito a participar activamente en este encuentro. Estoy convencida de que con el aporte y el entusiasmo de todos lograremos concretar los objetivos propuestos. 